\title{
Thermal Stress Analysis of Solar Thermochemical Reactor Using Concentrated Solar Radiation
}

\section{H. Zhang, S. J. Pang, Z. J. Luo, Y. Shuai, and H. P. Tan}

Key Laboratory of Aerospace Thermophysics of MIIT, Harbin Institute of Technology, Harbin 15001, China

\section{Abstract}

Utilizing solar thermochemical reactor to convert exhaust gas into high-quality clean fuel by concentrated solar radiation is a valuable way to develop renewable energy. Due to the high working temperature, the issue of reactor damage occurs easily as found during the course of the experiment. In order to find out the reasons, some thermal stress simulation and analysis of solar thermochemical reactor were made

Corresponding Author:

Y. Shuai

shuaiyong@hit.edu.cn

Received: 14 September 2018

Accepted: 1 October 2018

Published: 14 October 2018

Publishing services provided by Knowledge $\mathrm{E}$

(c) $\mathrm{H}$. Zhang et al. This article is distributed under the terms of the Creative Commons

Attribution License, which permits unrestricted use and redistribution provided that the original author and source are credited.

Selection and Peer-review under the responsibility of the ASRTU Conference Committee.

\section{G OPEN ACCESS}

in this article. The areas where thermal stress is concentrated were investigated in the contour simulation results. Based on the analysis, some suggestions for structural optimization for further research were formulated.

Keywords: solar thermochemical, thermal stress, heat transfer and flow, reactor

\section{Introduction}

Due to the increasing demand for clean energy, the application of solar energy has become an indispensable form of alternative energy use in modern society $[1,2]$. Nowadays, a solar-driven thermochemical reaction system using concentrated solar radiation for hydrogen and syngas (mainly $\mathrm{H}_{2}$ and $\mathrm{CO}$ ) production is considered to be an effective alternative to traditional fossil fuels to solve energy problems and climate change, which have attracted tremendous interests worldwide [3, 4]. The Computational Fluid Dynamics (CFD) simulation offers the possibility to investigate operating conditions of the solar thermochemical reactor [5]. Moller et al. [6] developed a one-dimensional unsteady and steady-state heat transfer model for a solar reactor of simple construction to analyze the thermal decomposition of $\mathrm{ZnO}$. Soon afterward, Moller and Palumbo [7] have designed a cylindrical solar chemical reactor taking advantage of inert gas to keep the reactor's window clean of $\mathrm{Zn}$ and ZnO. A Monte-Carlo ray-tracing method coupled with optical properties was developed by 
Shuai et al. [8] to predict radiative properties of solar reactor with quartz window. Costandy et al. [9] developed different struts of spherical and cylindrical solar reactor to investigate the effect of reactor geometry on the temperature distribution and heat loss inside the reactors. Thomey et al. [10] have developed a multi-chamber solar porous media reactor design for the decomposition of sulphuric acid. Since the metal oxide is being regenerated during the process, Konstandopoulos and Agrofiotis [11] have designed a two-reactor 'Conti-reactor' chamber to solve the intermittent problem relative to hydrogen production.

In reaction process, the concentrated solar energy is transmitted into the reactor inner cavity through a transparent quartz glass window installed on the front surface of reactor, which provides the necessary energy for reaction process. However, the processes of cracking and reforming would not happen until the operating temperature reaches at least $1000 \mathrm{~K}$ [12]. During the experiment, we have found a significant problem that the quartz glass window might break due to high heat flux. In the meanwhile, the $\mathrm{Al}_{2} \mathrm{O}_{3}$ ceramic insulation cavity also has a possibility of fragmentation as a result of thermal expansion.

In view of the aforementioned problems, the thermal stress of solar thermochemical reactor using concentrated solar radiation is investigated in this article to find out the broken conditions of solar thermochemical reactor and provide useful references for further study.

\section{Methods}

\subsection{Solar radiation convergence model}

Figure 1 shows the process of light convergence from the solar simulator to the solar thermochemical reactor under ideal conditions. This process including model building and numerical simulation was finished by the TracePro7o software with Monte Carlo ray tracing (MCRT). Based on the current experimental conditions and simulation requirements, the power of Xe lamp is set to be $6 \mathrm{~kW}$. The first focal length $c_{1}$ and the second one $c_{2}$ are 100 and $1000 \mathrm{~mm}$, respectively, so that we can obtain the eccentricity of ellipse $e$, the value of which is 0.818 . For convenient calculation, the solar thermochemical reactor is substituted with a circular incident surface, so that we can show the incident heat flux more clearly. 


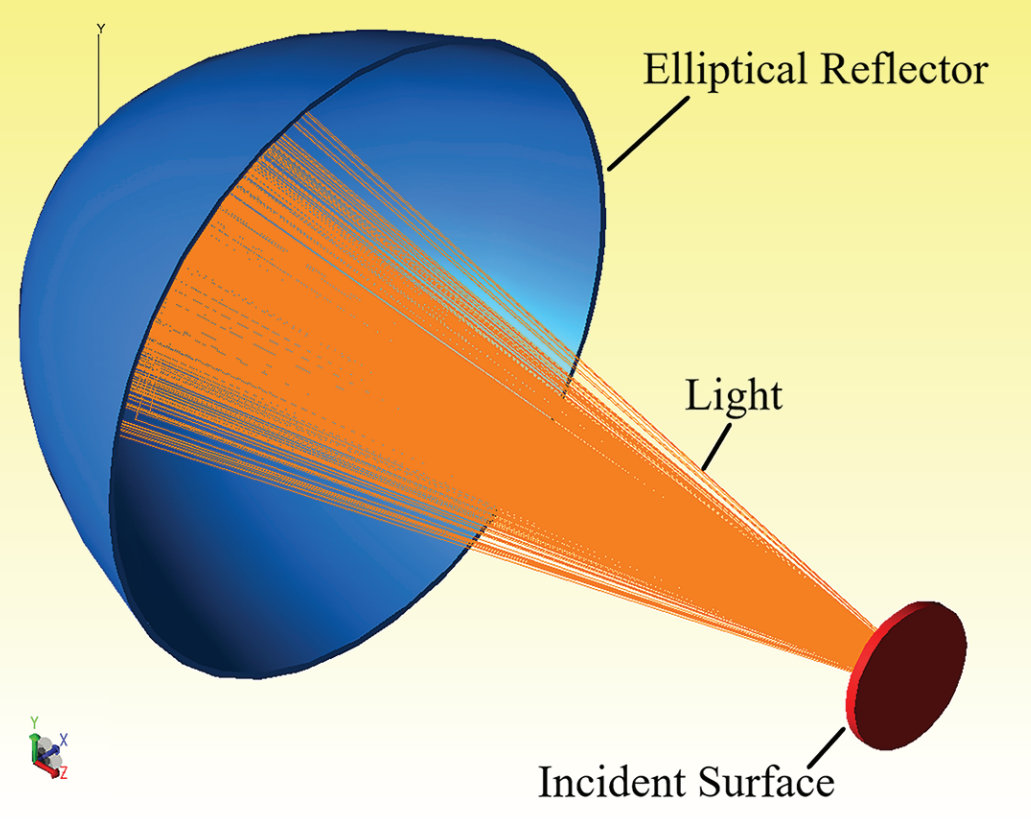

Figure 1: Schematic diagram of light convergence process.

\subsection{Solar thermochemical reactor model}

Figure 2 indicates the structure of solar thermochemical reactor. As shown in this figure, the whole reactor is made of $\mathrm{Al}_{2} \mathrm{O}_{3}$ ceramic thermal insulation for protecting the reactor and reducing heat loss during the progress of thermochemical reactions. The concentrated solar energy will be transmitted into the reactor inner cavity through the transparent quartz glass window installed on the front surface of the reactor, and the reactant gas will be led into the reactor inner cavity by four opposite inlets in the meanwhile, so that the oxidation-reduction reaction occurs under the action of catalyst in the lumen. In order to obtain the reaction temperature, two thermocouples are installed in the light incident area and reaction area, respectively.

The heat transfer and fluid flow characteristics of solar thermochemical reactor were obtained by the FLUENT software. In order to simulate the incident radiation more realistically, DO model was selected to figure out the radiation heat transfer. Considering the small import fluid velocity of $0.005 \mathrm{~m} / \mathrm{s}$, the laminar flow model was chosen to calculate flow characteristics. The absorption and scattering coefficients of quartz window were ignored due to high transmission. The incident heat flux calculated by TracePro7o software is used as the thermal boundary condition for the heat transfer and flow simulation. The other boundary conditions are given as follows:

Gas inlet: $T_{\mathrm{f}}=300 \mathrm{~K}$

Outside wall: $h=5 \mathrm{~W} /\left(\mathrm{m}^{2} \cdot \mathrm{K}\right) \quad T_{\text {air }}=300 \mathrm{~K}$ 


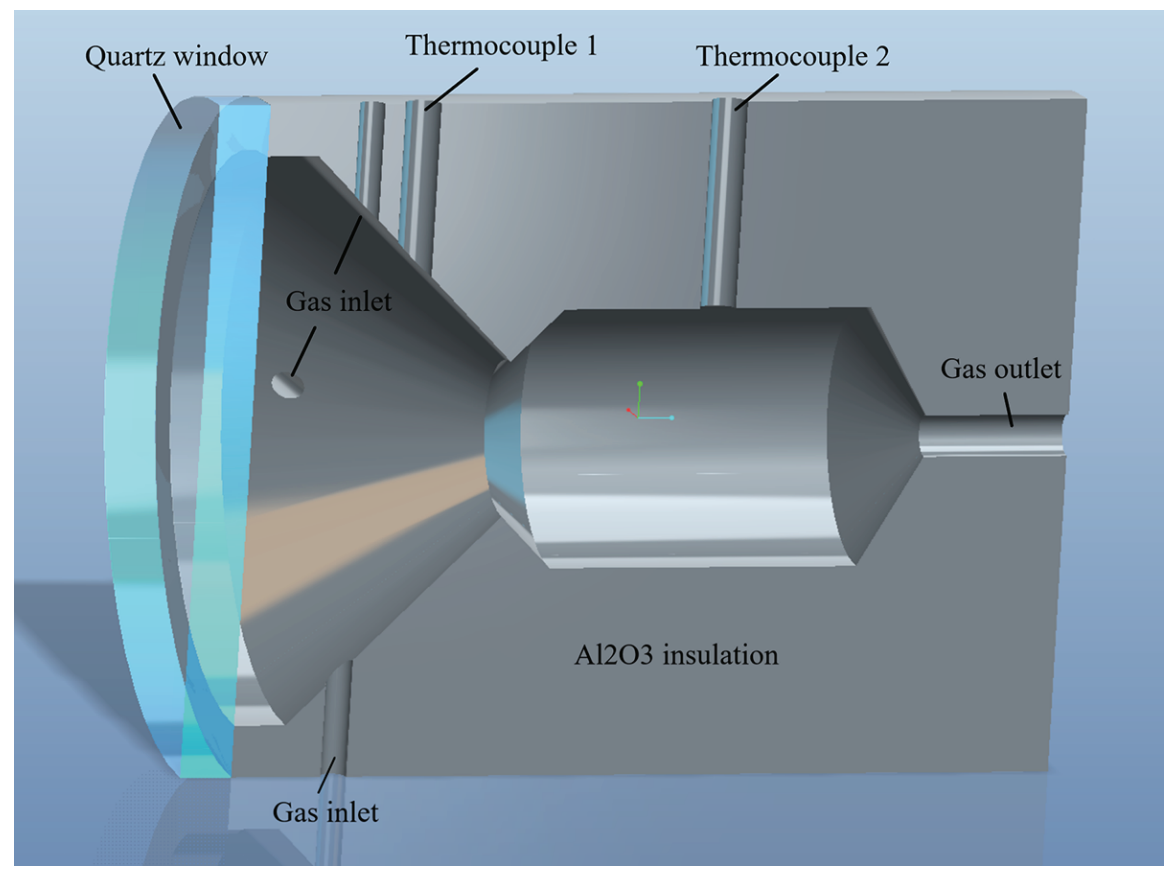

Figure 2: Structure diagram of solar thermochemical reactor.

Outlet: $\frac{\partial T_{\mathrm{f}}}{\partial x}=\frac{\partial T_{\mathrm{f}}}{\partial y}=0$

Due to the high working temperature environment, the thermal capacity of air is defined as [13]:

$$
c_{\mathrm{p}}=1.06 \times 10^{3}-0.449 T_{\mathrm{f}}+1.14 \times 10^{-3} T_{\mathrm{f}}^{2}-8 \times 10^{-7} T_{\mathrm{f}}^{3}+1.93 \times 10^{-10} T_{\mathrm{f}}^{4}
$$

The conductivity is [13]:

$$
\lambda=-3.93 \times 10^{3}+1.02 \times 10^{-4} T_{\mathrm{f}}-4.86 \times 10^{-8} T_{\mathrm{f}}^{2}+1.52 \times 10^{-11} T_{\mathrm{f}}^{3}
$$

Moreover, the thermal stress analysis of solar thermochemical reactor was accomplished by ANSYS Mechanical APDL 16.0 software after obtaining the results of heat transfer and fluid flow characteristics. Besides, the other physical parameters for simulation are given in Table 1.

TABLE 1: Thermal-physical and structural properties of materials [14-17].

\begin{tabular}{l|c|c|c|c|c|c|} 
Materials & $\begin{array}{c}\rho \\
\left(\mathbf{k g} / \mathbf{m}^{3}\right)\end{array}$ & $\mathbf{c}_{p}(\mathrm{~J} /(\mathbf{k g ~ K}))$ & $\mathbf{k}_{c}(\mathrm{~W} /(\mathbf{m ~ K}))$ & $\mathbf{E}(\mathrm{GPa})$ & $\begin{array}{c}\alpha \\
(\times 10- \\
\left.\mathbf{6} /{ }^{\circ} \mathrm{C}\right)\end{array}$ \\
\hline
\end{tabular}




\section{Results}

\subsection{Incident heat flux of reactor}

Figure 3 indicates the contour and $x$-axis energy distribution of incident heat flux on the quartz window front surface calculated by TracePro70 software, respectively. As shown in this figure, the spots at the center present several perfect concentric circles, which indicates that the amount of the light used in the simulation with MCRT is sufficient for the accuracy. According to the heat flux distribution data, a Gaussianbased energy density formula can be fitted by OriginPro8 software as follow format:

$$
q_{\mathrm{w}}=q_{0}+\mathrm{A} \times \exp \left[-0.5 \times\left(\frac{x}{\omega}\right)^{2}\right] .
$$

When the luminous flux is set to be $6 \mathrm{~kW}$, the aforementioned formula can be expressed as:

$$
q_{\mathrm{w}}=-32482.3+461347.9 \times \exp \left[-0.5 \times\left(\frac{x}{0.00528}\right)^{2}\right] .
$$

According to the fitting result, the value of R-Square is 0.99986 , which is accurate enough for the simulation.
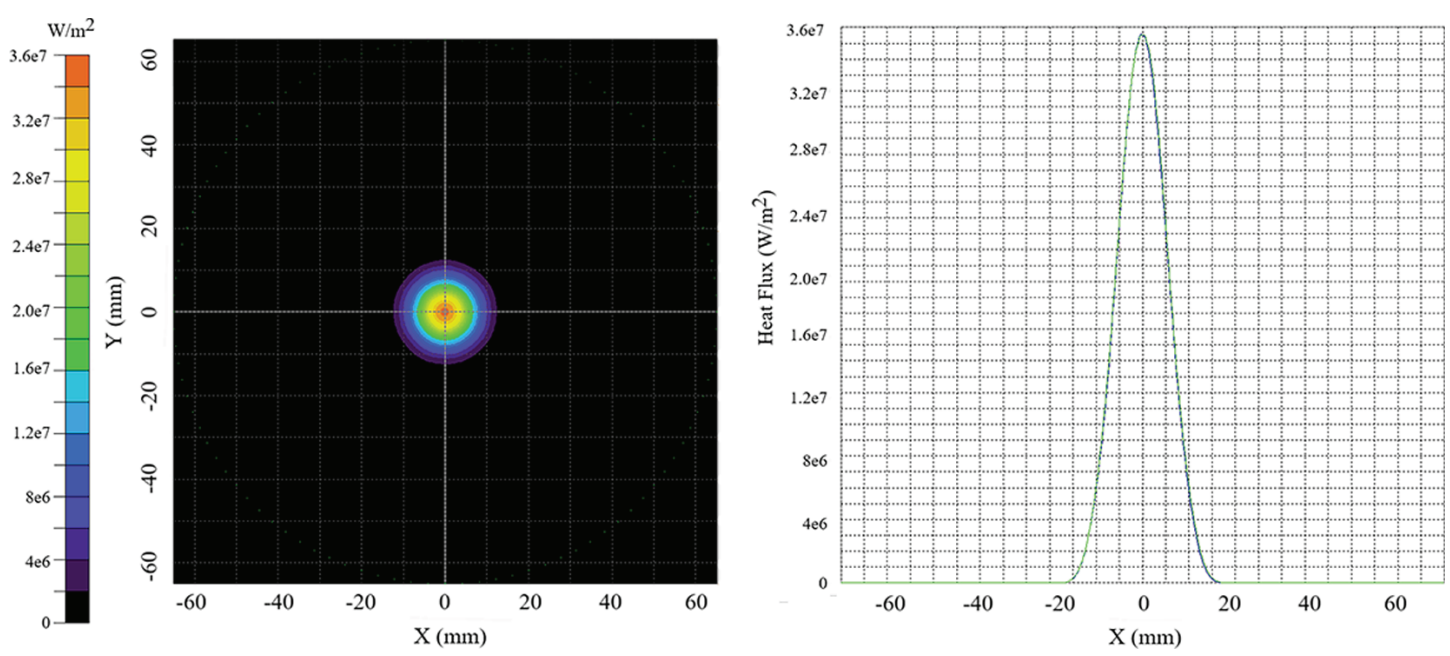

Figure 3: Contour (left) and $x$-axis energy distribution (right) of incident heat flux.

\subsection{Heat transfer and flow characteristics}

The analysis of heat transfer and fluid flow characteristics of solar thermochemical reactor was finished by Fluent software, and the incident heat flux formula was added by Users-Defined Functions (UDFs). Grid independence tests have been carried out 
before the calculation. Figure 4 shows the temperature and velocity distribution contours of solar thermochemical reactor, respectively. As indicated in Figure 4, the incident radiation mainly focused on the areas near aperture due to the effect of light convergence.
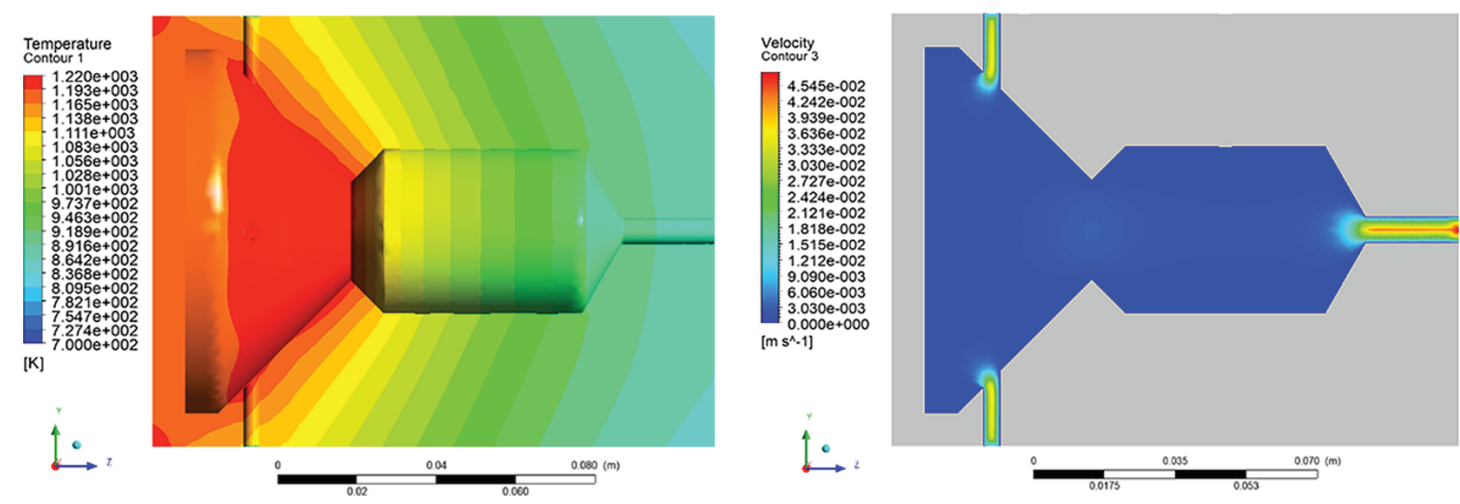

Figure 4: Temperature and velocity distribution contours of solar themochemical reactor.

\subsection{Analysis of thermal stress}

This section will discuss the thermal stress of quartz window and $\mathrm{Al}_{2} \mathrm{O}_{3}$ ceramics thermal insulation, respectively. To simplify the calculation, the way to add displacement load was adopted in this article. Figure 5 indicates the von Mises stress of quartz window. Note that only the edge portion of the quartz window was loaded, because only this portion is connected to the fastener. As shown in this figure, the maximum stress appears in the junction of the load portion and free portion, followed by the central area. When the thermal stress reaches $128 \mathrm{MPa}$, the quartz window will be broken, so it is safe under the current conditions.

The result of von Mises stress distribution of $\mathrm{Al}_{2} \mathrm{O}_{3}$ ceramic thermal insulation is shown in Figure 6. It can be observed that most of the thermal stress is concentrated on the front of the reactor, especially in the incident radiation areas. Obviously, the maximum stress of $12.5 \mathrm{MPa}$ occurs in the middle of the gas inlet and thermocouple socket. Due to the smallest thickness in this part, it is more likely to break. This phenomenon was also observed in previous experiment. Thus, it is recommended to avoid the situation, where two holes are too close to each other. Moreover, the edge of radiation entrance, as well as the vicinity of the aperture, is also the region of stress concentration. Although the compressive strength under ideal conditions is 850 $\mathrm{MPa}$, the ceramics still can be broken because of the high temperature environment, excessive local concentration thermal stress, etc. 


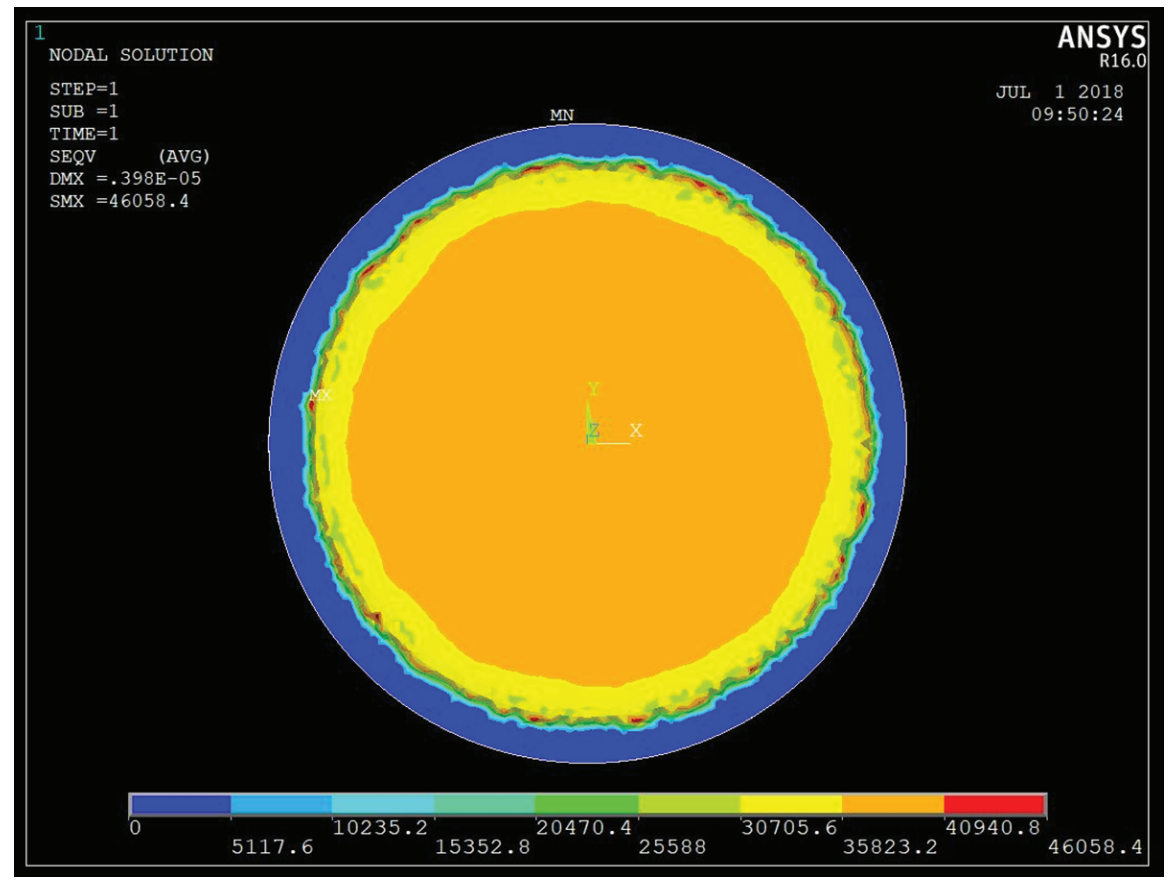

Figure 5: Von Mises stress distribution of quartz window.

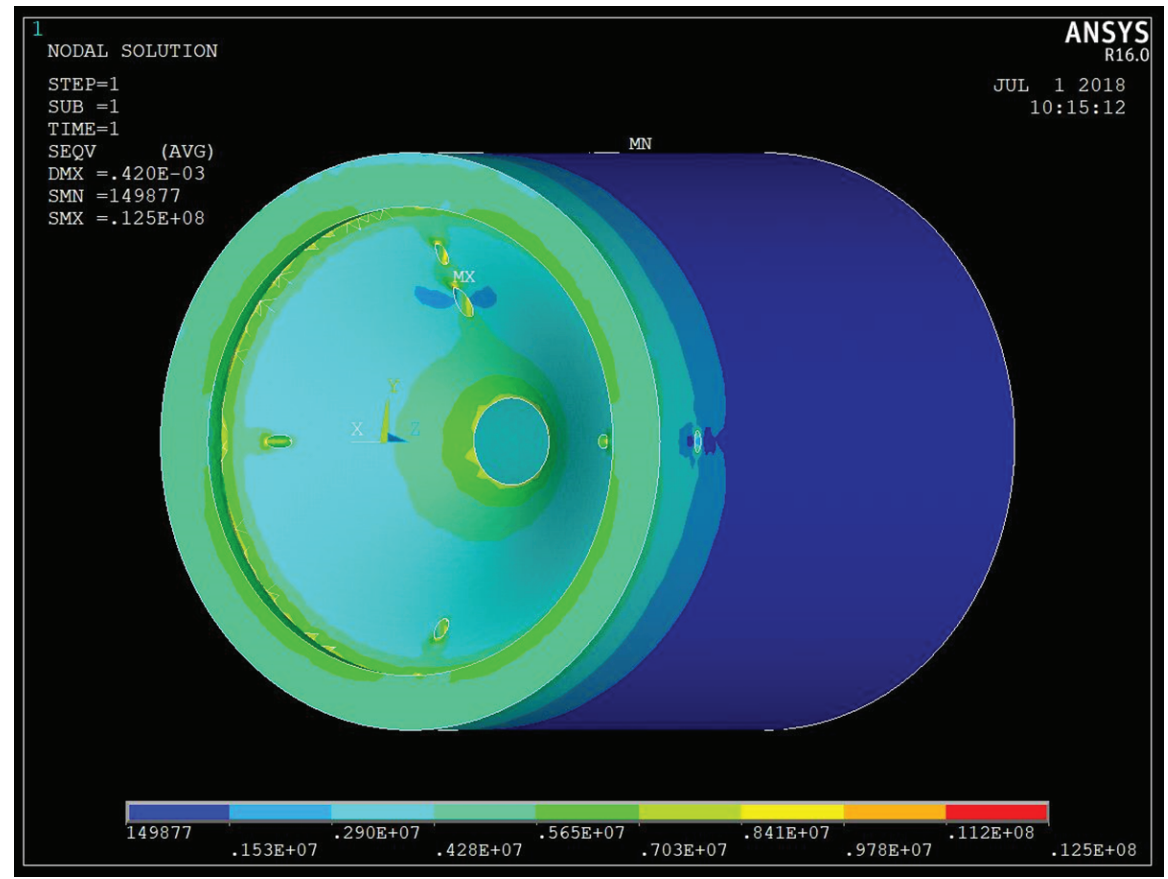

Figure 6: Von Mises stress distribution of $\mathrm{Al}_{2} \mathrm{O}_{3}$ ceramics thermal insulation.

\section{Conclusion}

According to the simulation results, the incident heat flux on the front surface of solar thermochemical reactor has a symmetrical Gaussian distribution, which can be programmed as heat boundary condition into the Fluent software by UDFs. Based on the 
analysis of thermal stress, it is recommended to increase the distance between gas inlet and thermocouple socket to prevent stress concentration. Besides, the sharp edge of ceramics is also one of the places that are prone to thermal stress.

\section{Funding}

This work was supported by the National Natural Science Foundation of China (Nos. 51522601, 51436009) and Fok Ying-Tong Education Foundation of China (No.141055).

\section{References}

[1] Steinfeld, A. (2005). Solar thermochemical production of hydrogen - A review. Solar Energy, vol. 78, no. 5, pp. 603-615.

[2] Hosseini, S. E. and Wahid, M. A. (2016). Hydrogen production from renewable and sustainable energy resources: Promising green energy carrier for clean development. Renewable \& Sustainable Energy Reviews, vol. 57, pp. 850-866.

[3] Yadav, D. and Banerjee, R. (2016). A review of solar thermochemical processes. Renewable \& Sustainable Energy Reviews, vol. 54, pp. 497-532.

[4] Marxer, D., Furler, P., Takacs, M., et al. (2017). Solar thermochemical splitting of $\mathrm{CO}_{2}$ into separate streams of $\mathrm{CO}$ and 0-2 with high selectivity, stability, conversion, and efficiency. Energy \& Environmental Science, vol. 10, no. 5, pp. 1142-1149.

[5] Meier, A., Ganz, J., and Steinfeld, A. (1996). Modeling of a novel high-temperature solar chemical reactor. Chemical Engineering Science, vol. 51, no. 11, pp. 3181-3186.

[6] Moller, S. and Palumbo, R. (2001). Solar thermal decomposition kinetics of ZnO in the temperature range 1950-2400 K. Chemical Engineering Science, vol. 56, no. 15, pp. $4505-4515$

[7] Moखller, S. and Palumbo, R. (2001). The development of a solar chemical reactor for the direct thermal dissociation of zinc oxide. Journal of Solar Energy Engineering, vol. 123, no. 2, pp. 83-90.

[8] Shuai, Y., Wang, F. Q., Xia, X. L., et al. (2011). Radiative properties of a solar cavity receiver/reactor with quartz window. International Journal of Hydrogen Energy, vol. 36, no. 19, pp. 12148-12158.

[9] Costandy, J., El Ghazal, N., Mohamed, M. T., et al. (2012). Effect of reactor geometry on the temperature distribution of hydrogen producing solar reactors. International Journal of Hydrogen Energy, vol. 37, no. 21, pp. 16581-1659o. 
[10] Thomey, D., Oliveira, L., Säck, J. P., et al. (2012). Development and test of a solar reactor for decomposition of sulphuric acid in thermochemical hydrogen production. International Journal of Hydrogen Energy, vol. 37, no. 21, pp. 16615-16622.

[11] Konstandopoulos, A. G. and Agrofiotis, C. (2006). Hydrosol: Advanced monolithic reactors for hydrogen generation from solar water splitting. Revue des Energies Renouvelables, vol. 9, pp. 121-126.

[12] Lougou, B. G., Shuai, Y., Xing, H., et al. (2017). Thermal performance analysis of solar thermochemical reactor for syngas production. International journal of Heat and Mass Transfer, vol. 111, pp. 410-418.

[13] Wu, Z., Caliot, C., Flamant, G., et al. (2011). Coupled radiation and flow modeling in ceramic foam volumetric solar air receivers. Solar Energy, vol. 85, no. 9, pp. 23742385 .

[14] Huang, X., Chen, X., Shuai, Y., et al. (2015). Heat transfer analysis of solar-thermal dissociation of $\mathrm{NiFe}_{2} \mathrm{O}_{4}$ by coupling MCRTM and FVM method. Energy Conversion and Management, vol. 106, pp. 676-686.

[15] Pietrzak, K., Kalinski, D., and Chmielewski, M. (June 19-23, 2005). Interlayer of $\mathrm{Al}_{2} \mathrm{O}_{3}-\mathrm{Cr}$ functionally graded material for reduction of thermal stresses in aluminaheat resisting steel joints, in 9th Conference and Exhibition of the European-CeramicSociety. European Ceramic Society.

[16] Tibeica, C., Damian, V., and Muller, R. (October 17-19, 2011). SiO 2 -Metal Cantilever Structures Under Thermal and Intrinsic Stress, in 34th International Semiconductor Conference (CAS). IEEE.

[17] Wang, K., Li, W. F., and Du, J. (2016). Thermal analysis of in-situ $\mathrm{Al}_{2} \mathrm{O}_{3} / \mathrm{SiO}_{2}(\mathrm{p}) / \mathrm{Al}$ composites fabricated by stir casting process. Thermochim Acto, vol. 641, pp. 29-38. 